\title{
Doğu Trakya Bölgesi Halk Müziğinde Ritim Kalıplarına Dair Bir İnceleme*
}

\author{
Canan AYKENT**
}

\begin{abstract}
ÖZ
Trakya bölgesi halk müziği müzikologlar için zengin öğelere sahiptir. Bulgar-Yunan-Slav-Arnavut-Romen-Türk-Çingene toplulukları, 20. Yüzyıl başına kadar yedi yüzyıl hem birlikte hem kendi içlerinde sürdürdükleri yaşamla çokkültürlü bir yapı sergilemiş̧lerdir. 19. Yüzyılın sonlarından itibaren bağımsızlık hareketleri ve Osmanlı İmparatorluğu'nun dağılı̧ dönemiyle beraber yeni çizilen sınırlara göre farklı devletler oluşmuş ve bunun sonucu her topluluk kendi devletinin sınırlarına göç etmiştir. Doğu Trakya’nın Türkiye sınırları içinde kalan kentleri, Edirne, Kırklareli, Tekirdağ ve İstanbul'un bir kısmıdır. Bölgenin nüfusunu Balkanlar'dan göç eden Türkler ve Çingeneler oluşturmaktadır.

Trakyàda yaşayan topluluklar müzik kültürü açısından, çalgilarda, ezgilerde, ritimlerde ve dilde, bir yandan ortak, benzer unsurlar geliştirmiş bir yandan da kendi kimliklerini korumuşlardır. Genellikle her topluluk, kendi içinde kasaba bazında bir arada yaşamıştır. Bununla beraber toplulukları kaynaştıran, kasabalar arası ticaret ve düğün gibi sosyal etkinlikler olmuştur. Müzisyenler, bir kasabadan diğerine geçerek birbirlerinin etkinliklerinde çalmışlar, böylelikle hem öteki müzikleri öğrenmiş hem kendi müziklerini aktarmışlardır. Bu nedenle müzik, topluluklar arası ortak kültürün oluşturulmasında en etkin araçlardan biri olmuştur. Ritim bilgisi açısından ise bölgenin en karakteristik özelliği "aksak" tartımlardır. 5, 7, 9,11,13,15 zamanlı ritim kalıpları en gelişmiş çeşitlemeleriyle bu coğrafyada çalınmaktadır. Doğu Trakyada
\end{abstract}

Bu çalışma, 2002 yılında, Hacettepe Üniversitesi Ankara Devlet Konservatuvarı Etnomüzikoloji ve Folklor Anabilim Dalı'nda “Asma Davulun Trakya Bölgesi'ne Özgü Ritmik Yapısı" konulu Yüksek Lisans tezimden hazırlanmıştır.

** $\quad$ Dr, T.C. Kültür ve Turizm Bakanlığı, Güzel Sanatlar Genel Müdürlüğü, ATDMT, Ankara/Türkiye E-posta: cananaykent@yahoo.com.tr, ORCID: 0000-0002-1212-425X, DOI: 10.32704/erdem.838421 Makale Gönderim Tarihi: 11.02.2020 * Makale Kabul Tarihi: 22.07.2020 * (Sanat ve Edebiyat Mk.) 
5, 10 ve 9 zamanlı tartımlar öne çıkmakta, Batı Trakya'da ise 7, 9, 11 ve üstü zamanlılar dikkati çekmektedir. Çalgılar içinde davul-zurna ikilisi meydan sazlarının temsilcileridir. Dolayısıyla horo ve karşılama oyun havaları repertuarın temelini oluştururlar.

Halk müziği derlemelerinde ezgilerin notaya alınması, araştırmaların büyük çoğunluğunu oluşturmaktadır. Buna karşın ritme ilişkin bilgiler ise genel olarak tempo ve tartımın yazılması ile sınırlı kalmaktadır. Ritim kalıpları, tempo ve tartıma bağlı olarak yöresel tavırlara ve davulcunun yaratıcılığına göre eser boyunca çok çeşitli olabildiği gibi çok yalın da çalınabilmektedir. Bu bağlamda ritimlerin yöresel karakteristiklerini belirlemek göründüğünden daha karmaşıktır. Çalışmanın amacı, Doğu Trakya’nın Edirne, Kırklareli ve Tekirdağ halk müziğinin horo ve karşılama repertuarı içinden seçilmiş eserlerde çalınan ritim kalıplarından örnekler vererek bölge ritimleri üzerine bilgi birikimine katkıda bulunmaktır. Notaları yazılan ritim kalıpları eser boyunca en sık çalınanlar arasından seçilmiştir. Aynı repertuar üzerinde yapılmış ve yapılacak diğer icra incelemeleri yöre karakteristiklerini belirlemek adına önemlidir. Türkiye dışında diğer ülkelerde de uygulanacak benzer araştırmaların, Trakya kültür mirasının ritmik yapısına ilişkin genel bir harita oluşturulması açısından faydalı olacağı düşünülmektedir.

Anahtar Kelimeler: Çokkültürlülük, Trakya Bölgesi, halk müziği, ritim, davul 


\title{
A Study About Rhythmic Pattern on Eastern Thrace Region Music
}

\author{
ABSTRACT \\ The Thracian region folk music has rich elements for musicologists. \\ Bulgarian-Greek-Slavic-Albanian-Romanian-Turkish-Gypsy \\ societies displayed a multicultural structure by co-existing with the \\ society and by leading a life within themselves for 700 years until \\ the beginning of the 20th century. Together with the independence \\ movements and the dissolution period of the Ottoman Empire since \\ the late 19th century, different states have been formed according to \\ the newly drawn borders, and as a result, each society has migrated to \\ the borders of its own state. The cities of Eastern Thrace remaining \\ within the boundaries of Turkey, are Edirne, Kırklareli, Tekirdağ and a \\ part of Istanbul. The population of the region is of Turks and Gypsies \\ who has immigrated from the Balkans.
}

Thracian societies, in terms of music culture developed similar elements in the instruments, melodies, rhythms and language, on the other hand, they have preserved their identities. Generally, each society lived together on a town basis. What united societies was their social activities such as inter-town trade and weddings. The musicians moved from one town to another and played in each other's events, so they both learned the other music and transferred their own music. For this reason, music has been one of the most effective tools for creating a cross-community culture. In terms of rhythm knowledge, the most characteristic feature of the region is "odd" meters. 5, 7, 9, 11, 13,15-time rhythmic patterns are played in this geography with the most advanced variations. In Eastern Thrace, 5, 10 and 9-time meters stand out, and in Western Thrace, 7, 9, 11 and above times attract attention. As instruments drum-zurna duo are representatives of the musical instruments. Therefore, horo and karşlama dance music form the basis of the repertoire.

In folk music compilations, majority of the research is based on the transformation of tunes into note forms. In contrast knowledge regarding rhythm is generally limited to the writing of tempo and meters. Rhythmic patterns, depending on the tempo and meters, can be played very plainly as well as variously depending on the local attitudes and the creativity of the drummer. In this context, it may be more complex than it seems to determine the local characteristics of rhythms. The aim of the study is to contribute to the regional folk music by compiling knowledge on the rhythmic patterns which are played in the horo and chosen from the karşlama repertoire of the folk music of Edirne, Kırklareli and Tekirdağ in Eastern Thrace. Rhythmic 
patterns whose notes are written, were chosen among the most frequently played throughout the work. Other executive investigations conducted and to be carried out on the same repertoire are important for determining local characteristics. It would be useful to conduct a similar reaseach in other countries other than Turkey in order to create a general map of Thracian cultural heritage in terms of rhythmic structure.

Keywords: Multiculturalism, Thrace Region, folk music, rhythm, drum 


\section{Giriş}

7 ürk halk müziği derlemelerinde günümüze kadar yapılan çalısmaların 1 geneli ezgilerin tespit edilmesi ve notaya aktarılması üzerine olmuştur. Ezgilerin yanı sıra müziği oluşturan diğer unsur, ritimlerin tespiti, sınırlı sayıda araştırmalarda yer almaktadır ${ }^{1}$. Davul, halk müziğinin meydan çalgısıdır. Davul icracıları baba-oğul ya da usta-çırak ilişkileri ile yetişmektedirler. Köyden kente göçler ve kent kültürünün giderek yaygınlaşması, geleneksel icraların değişmesine/dönüşmesine, yok olmasına yol açmaktadır. Bu nedenle icraların kayıt altına alınması, tarihsel geçmişi ve folklor değerlerini tanımak, anlamak açısından bugün daha da önem kazanmıştır. Bu bakımdan ritmik yapıya ilişkin bilgilerin, sözel kültürden yazılı kültüre geçirilmesi, kaybolmaya yüz tutmuş veya tutmakta olan değerleri belirlemek, referans kaynakların oluşturulmasını sağlamak ve dolayısıyla bu alandaki eksiklikleri tamamlamak için gereklidir.

13. yüzyıldan 20. yüzyıl başlarına kadar Osmanlı İmparatorluğu'nun egemenliği altında olan Trakya Bölgesi, Yunan, Bulgar, Arnavut, Slav, Romen, Türk ve Çingene topluluklarının yaşadığı yerleşim alanıdır. Bu coğrafyada yıllar içerinde devletler kurulmuş, göçler yaşanmış, sürekli hareketlilik söz konusu olmuştur. Türkiye'nin sınırlarının son şekli, 1920 yılında imzalanan Sevr Antlaşması ile belirlenmiştir. Marmara Bölgesi'nin Avrupa kıtasına en yakın toprakları olan Doğu Trakya adı verilen bu kesim, Edirne, Kırklareli, Tekirdağ ve İstanbul kentinin bir kısmından oluşmaktadır. Bölgenin kültürel yapısı ise Trakya'nın çokkültürlü mirasını yansıtır.

Araştırmada, Trakya müzik kültürü bağlamında Doğu Trakya’ya özgü özellikler ve bunun içinde ritmik yapı incelenmeye çalışılmıştır. Amaç, ritim kalıplarından örnekler derleyerek bu alanda yazılı kültüre katkıda bulunmaktır.

\section{1. Çokkültürlülük Bağlamında Müzik}

Trakya yöresinin müzikal yapısını, Slav-Arnavut-Yunan-Bulgar-RomenÇingene topluluklarının oluşturduğu Balkan kültürleri ile Orta Asya’dan

1 Trakya bölgesinde çalınan ritim kalıplarına dair yapılan çalışmalar yayınlanmamış lisans üstü tezlerde ve bir kitapta yer almaktadır. Tespit edebildiklerim şunlardır: Mehmet Erdinç Kadığu’nun Kırklareli İlinde Yaygın Olarak Kullanılan Halk Oyunları Ezgilerinin Ritmik Yapilarının İncelenmesi (1993), Nihal Dudu'nun Türk Halk Oyunlarında Oyun ve Müzik Ritimlerinin Karşılıklı İlişsisi (1994), Serpil Mürtezaoğlu'nun Türk Halk Oyunları Müziklerinin Ritmik Analizi (1995), Atilla Sağlam’nn Tarihi Kırkpınar Yağlı Güreş Musikisi "Pehlivan Havaları”, Mustafa Şahin’in Türk Halk Oyunları Türlerine Göre Asma Davulun İncelenmesi (2009), Erkan Kanat'ın Trakya'da Yaşayan Romanların Düğünlerinde Asma Davulla İcra Ettikleri Dokuz Zamanlı Ritmik Yapılar (2011) ve Melih Duygulu'nun Türkiye'de Çingene Müziği (2006) adlı kitabı. 
izler taşıyan Anadolu Türk topluluklarının kültürü oluşturmaktadır. Karadeniz, Marmara Denizi, Ege Denizi, Rodop ve Balkan Dağları arasında kalan bu coğrafyada, belirtilen topluluklar, asırlardan beri kasaba bazında homojen gruplar olarak birbirine komşu veya birbiriyle yan yana yaşamışlardır. Dil ve din bakımından farklı olan bu toplulukları ekonomik ilişkileri dışında kültürel açıdan bir araya getiren en önemli faktörlerden biri müziktir; çünkü müzisyenler yalnızca kendi etnik gruplarında değil, komşularının da törenlerinde çalmışlardır ${ }^{2}$. Bu nedenle hem birbirlerinin şarkılarını öğrenmiş hem de bu şarkıları diğer topluluklara taşımışlardır. Genel olarak Batı Trakya'da yüzyıllardan beri yerleşik olan Slav-Yunan-Latin topluluklarının halk ve dini müzikleri temel yapıyı oluşturur. Doğu Trakya'da da Türklerin halk müziği ağırlıklıdır. Bununla birlikte her kültürün bir diğerini etkilediği, ortak ezgi ve ritimlerin paylaşıldığı hatta sözlerin kendi dillerine tercümesiyle aynı şarkıların seslendirildiği görülmektedir. Bu etkileşimler karşılıklı iki topluluk arasında olmanın ötesinde karmaşık ilişkiler ağını da beraberinde getirmiştir. Örneğin, Arnavut, Romen ve Bulgar halk müziklerinde Türk müziği etkilerinin görüldüğü, Gagavuz ve Bulgar Türklerinin Türk ve Romen halk şarkılarından, buna karşın Romen halk şarkılarının da Bulgar halk şarkılarından esinlenmiş olduğunu belirtilmektedir (Acaroğlu 1982: 10,13). 1878 Osmanl1Rus savaşının sonucu kaybedilen topraklardan gelen göçlerle Balkanlar'da yaşayan Türk halkı, atalarının Asya ve Anadolu'dan getirdikleri kültürel mirası diğer ulusların kültürleriyle harmanlayıp yeniden Meriç Nehri’nin doğusuna taşımışlardır (Artun 1992: 6).

\section{Kadim ikili: Davul-Zurna}

Davul-zurna ikilisi tüm yörede en temel çalgı grubudur. Yunanlilar çift anlamına gelen "zygia" sözcüğüyle bu ikiliye ayrı bir isim vermişlerdir ${ }^{3}$ Genel olarak Batı Trakya'da iki zurna bir davul, Doğu Trakya'da ise iki zurna iki davul yan yana yer alır. Zurna, Bulgarca "zurla”, Yunanca "zurnas", Arnavutça "zurne”, Slav topluluklarında "zurle/zurla" olarak adlandırılmaktadır. Davul ise Slavlarda “tıpan”, “tapan”, Arnavutlarda "daule”, Yunanlilarda "dauli”, "tabor”, Romenlerde "tabulhana” olarak geçmektedir (Kösemihal 1937: 370).

Music and Dance Tradition of Thrace, Greece's Northeastern Region. (http://www.ohfs.org).

Zournas \& Daouli: An Inseparable Musical Tradition. (file:///C:/Users/User/Pictures/uhfds.pdf).

Tapan kelimesi Gazimihal'e göre tavul'dan gelmektedir. Tavul, iki yüzü derili kasnaklar için kullanılır. Arapçada tavul için tabl kelimesi kullanılmıştır. (Gazimihal, 1975, s. 10) Farsçada tabl-han/tabilhane kelimesindeki 1 ve h'nın düşmesiyle tapan haline gelmiştir. Yugoslavyada bu h düşürmelerine rastlanmaktadır (Gazimihal, 1959). 
Yunanistan'da davul yapımında geçmişte, eşek, kurt ve öküz derilerinin kullanıldığ 1 , kasnak ölçülerinin 50-60 cm arasında olduğu ve tokmağa "kopanos", çubuğa "vergha” denildiği bilinmektedir ${ }^{5}$. Türkiye tarafinda Üngör'ün 1973 yılında yaptığı araştırmaya göre, Edirne, Kırklareli, Hayrabolu ve Keşan’da davulların çapları 45-55cm, kasnak genişlikleri 27-33cm arasındadır (1973: 227-228). 2002 yılında gerçekleştirilen Kırkpınar Güreşleri'nde çalan Edirne doğumlu, Selanik göçmenlerinden olan davulcu Adnan Örs'ten elde ettiğim bilgiye göre, kasnaklar, Mardin'den gelmekte, genişlikleri 30-40 cm ölçülerinde olacak şekilde davulcuların kendileri tarafindan imal etmektedir. Bas tarafinda keçi, dana ve oğlak, tiz tarafında ise pres-bant deriler kullanılmaktadır (Aykent 2002: 31-32).

\section{Tartımlar}

Balkan folklorunda ritimlerde en dikkat çeken unsur aksak tartımların zengin kullanımıdır. 5/8, 5/16, 7/8, 7/16, 9/8, 9/16, 11/16, 13/16, 15/16 gibi tartımlar oyun havalarının temelini oluşturur. Üngör, Balkanlar'da ve Türk müziğindeki ritimler için şu görüşü öne sürmektedir:

"Müşterek yönler incelenirken usullerin gösterdiği karakteristik hepsinden önce dikkati çeker. Balkanlar'da her yerden ziyade 5'li, 7'li, 9'lu, 11'li, 13'lü vs gibi aksak usuller ve diğerlerinin çeşidi o kadar işlenmiştir ki usul çeşitliliği 75-80'i bulmuştur. Aksaklar kendi aralarında dahi çeşitlenmiştir. Mesela 9 zamanlı aksak usulünden 4 çeşit, 11 zamanlıdan 3 çeşit vs. gibi tipik örnekler görülür. Zannederim Türk musikisi bu usul yönünden Balkan musikileri arasında en fazla çeşitliliğe ulaşmış musikidir” (Üngör 1985: 122).

5'li tartımın, $(2+3)$ ve $(3+2)$ dağılımı bölgenin genelinde yaygın olarak çalınmaktadır. 16'lık hızlı mertebenin (2+3) şekli, doğu Makedonya'da ayin ve Noel gibi dini müziklerde sıklıkla kullanılmaktadır. Buna karşın (3+2) şekline az rastlanmaktadır (Bugariska 1999). Türk kültüründe bu tartıma "Türk Aksağı" denilir. 7'liler ise Slav topluluklarının oyun havalarında en sık kullanılan tartımdır. Yaygın dağılım şekli $(3+2+2)$ 'dir. Türklerde "Devr-i Hindî” olarak adlandırılan bu dağılım, diğer Balkan ülkelerindeki kadar yaygın çalınmamaktadır. Bulgaristan'da 7'liler Makedonya'ya göre daha hızlı çalınmaktadır ve $(2+2+3)$ dağılımını daha çok kullanmaktadırlar (Bugariska 1999). Yunanistan'da da "Mantilato" oyunları 7/8'lik $(2+2+3)$ şeklinde oynanmaktadır'. Bu dağılım Türklerde "Devr-i Turan" adıyla bilinmektedir ve daha çok

Zournas \& Daouli: An Inseparable Musical Tradition. (file:///C:/Users/User/Pictures/uhfds.pdf).

6 Music and Dance Tradition of Thrace, Greece's Northeastern Region. (http://www.ohfs.org). 
16'lık mertebesi yaygındır. Mandıralar, köçekçeler ve oyun havalarında çalinmaktadırlar (Yarkın 2014: 22). 9/8 ve 9/16'liklar $(2+2+2+3)$ ve $(2+2+3+2)$ Doğu Trakya'da daha yaygın duyulurlar. Türk müziğinde 9/8'lik $(2+2+2+3)$ dağılıma "Aksak", 9/4'lük (4+5) dağılımına "Ağır Aksak", aynı dağılımın son 3'lüdeki vuruşlarının yer değiştirmiş şekline "Evfer”, $(2+3+2+2)$ dağılıma "Raks Aksağı", $(3+2+2+2)$ dağılımına "Oynak" denilmektedir (Özkan 1994: 596-609). Doğu Trakya'da yaşayan ve Batı Roman kolu olan Çingeneler 9/8'lik tartımın $(2+2+2+3)$ şeklinin yaygın çalınmasında en önemli rolü oynamaktadırlar. Öyle ki bu dağılıma "Roman ritmi" de denmektedir (Duygulu, 2006, s. 109). 10 zamanlı tartımlar Türklerde çok çeşitlidir. (2+3+2+3 veya 5+5) dağılımı "Aksak Semai" ismini alır. 10/16' lık hızlı mertebesine "Curcuna” denilmektedir. 10/4’lük ağır olanı "Lenk Fahte”dir. $(2+2+3+3)$ dağılımı "Ceng-i Harbi"dir (Yarkın 2014: 26-27). Batı Trakya'da 11 ve üstü tartıml1lar sıklıkla çalınmaktadırlar. 11'liler Bulgaristan, Makedonya ve Sırbistan'da "Kopanitsa" veya "Krivo" adıyla $(2+2+3+2+2)$ dağılımı ile daha yaygın çalınmaktadır . Türklerde $(2+3+2+2+2$ ya da $5+6)$ şeklinde "Tek Vuruş" ismiyle adlandırılır (Özkan 1994: 624) Halk müziğinde (7+4 ve 5+6) şekliyle çalınmaktadır (Üngör 1985: 123).

Basit ve bileşik ölçülerde ise en sık kullanılan tartımlar 2/4'lüktür. 3/4, 3/8, 9/8 $(3+3+3)$ gibi 3'lü dağglımlılar yöresel değildir ve Batı Avrupa'yla temas sonucu kentlerde yaygınlık kazanmıştır. 6/8'likler daha çok enstrümantal şarkılarda görülürler. Bunların dışında kimi eserler serbest yazılmıştır (Bugariska 1999).

\section{Bölgesel Oyun Havası Türleri ve İlgili Ritim Kalıpları}

"Horo" ya da hora olarak bilinen sözcük, Slav dilinde insanlar anlamına gelmektedir. Bulgarcada "horo", Makedoncada "oro", Romencede "ora", Pomakçada "huro", Sırpça ve Boşnakçada "kolo" olarak geçmektedir. Horolar, el ele, omuz omuza, kol kola ya da kuşak kuşağa tutuşarak, farklı ayak hareketleriyle oynanan kapalı daire şeklindeki oyunlara verilen isimdir (Çolakoğlu 1984: 245). Konuları, yiğitlik, kabadayılık, çatışmalar, serhat boyları, aşk ve günlük yaşam üzerinedir. Kimi eserlere kişi, ulus ve meslek isimleri verilmiştir. Çifte davul-zurna eşliğinde oynanmakta, yerine göre klarnet, kemençe, akordeon ve tulum gibi çalgıların eşlik ettiği görülmektedir (Uğurlu 2009: 528). Slav topluluklarında halk oyunlarının ruhunun horolar olduğu belirtilir (Acaroğlu 1982: 19). Bulgaristan ve Yunanistan'da en temel oyunlardan biridir. Horo'nun Yunanistan'daki adı "zonaradiko"dur. "Tsestos” sözcüğü

The Bulgarian Wedding. (http://ifccsa.org/bulgfolk.html). 
hızlı tempolu olanları ifade eder. "Stis Tris", "Trite Pati" olarak adlandırılan "Üç Ayak” oyunu ise hem Bulgarlar hem Yunanlılar hem de Türkler tarafindan oynanmaktadır. Zonaradiko'lar 2/4, 4/4, 6/8'lik tartımlarda da çalınır. Bulgaristan'da, "Pajduska” (Tripati, adıml 15/16), "Rachenitsa" (7/16), "Pravo" (düz, 2/4) ve "Povarnato" (dönüşlü 9/8) en bilinen horolardandır. Türklerdeki "Fatoş" oyununun da "Pajduska"dan geldiği düşünülmektedir. Aynı oyun Yunanistan ve Makedonya'da "Baidouska” adıyla yer almaktadır. Fatoş, Sırpça kız ismi olan Pajduska/Baidouska’ya göre daha ağır tempoda çalınmaktadır (Çolakoğlu 1984: 225). Esere ilişkin ritim kalıpları örnekleri aşağıdaki gibi derlenmiştir9.

Nota 1-2. "Fatoş" ritim kalıplar110

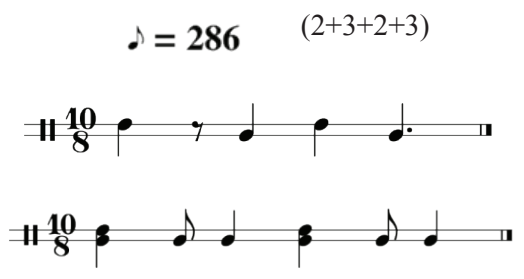

Serhat türküsü olan “Edirne’nin Ardı Bağlar”, en bilinen horolardandır.

Nota 3-4. Edirne'nin Ardı Bağlar ritim kalıplar1 ${ }^{11}$

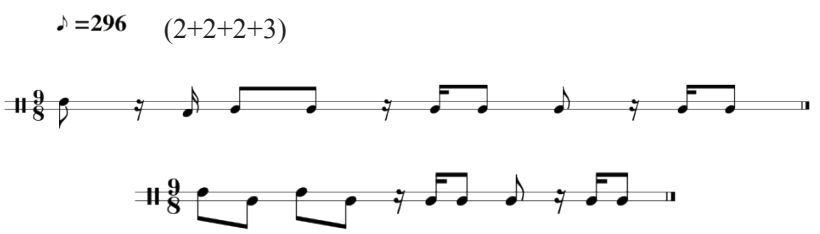

"Kabadayı" ve "Kasaplar" tüm Trakya genelinde ayrı bir yere sahiptir. Kabaday1, bölge yiğitlerine verilen payedir (Demirsipahi 1975: 291). Yiğitliğin, serhatlere, akınlara giden askerlerin düşmanlara meydan okuyuşunu simgeler. Bulgar, Yunan, Arnavut, Makedon ve Sırp halk müziklerinde "hajduk"

8 The Bulgarian Wedding. (http://ifccsa.org/bulgfolk.html) ve Music and Dance Tradition of Thrace, Greece's Northeastern Region. (http://www.ohfs.org).

9 Davul notası yazımında bas (tokmak tarafi) sesler üst çizgiye, tiz (çubuk tarafi) sesler alt çizgiye yazılmıştır. Tüm çarpmalar tiz tarafta çubukla yapılmaktadır. Kullandığım program bas tarafinda göstermiştir.

10 Fatoş: TRT arşivi Edirne Havaları kayıtları, Davulcu: Bekir Yanyacı.

11 Edirne'nin Ardı Bağlar: Trakyalı Metin Yanyacı ve Kardeşleri (kaset). 
(haydut), "kaçak", "komitacı", ya da "kleftes" olarak adlandırılan kabadayıların teması, 14. Yüzyıldan itibaren Osmanlı İmparatorluğu'na karşı geliştirdikleri çete savaşlarıyla ortaya çıkmış, hajduk türküleriyle çeteci yiğitler bu ulusların tarihlerinde ölümsüzlük kazanmıştır. Hajduk türkülerinde Türk ve Romenler arasında sevgiliye duyulan kıskançlık, Türk-Romen ilişkileri hakkında ilgi çekici tarihi haberler de yer almaktadır (Guboğlu 1982: 106). Türkiye'deki kabadayılarda ise tam tersine Balkan uluslarına karşı savaşılmaktadır. Selanikli göçmenlerce getirilen "ağır hava" da denilen çete oyunlarında tempo yavaş başlayıp yavaş bitmektedir (Ay 1999: 175). "Kabadayı Ahmet Bey", "Alay Bey" gibi örnekler kabadayı öykülerinde yer almış, bölgenin karakteristik eserlerinden bazılarıdır.

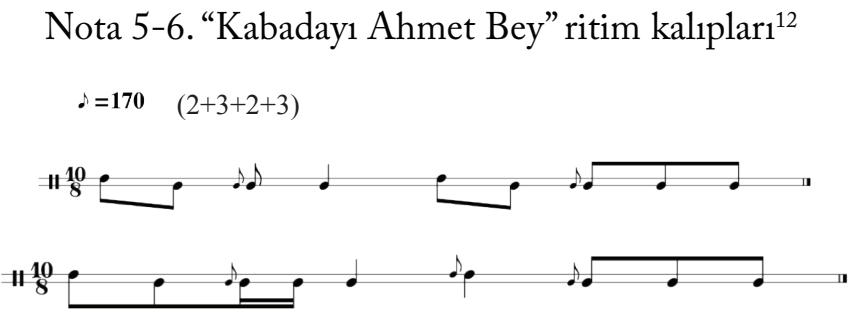

Nota 7-8. “Alay Bey (Bir Evler Yaptırdım)" ritim kalıplar1 ${ }^{13}$

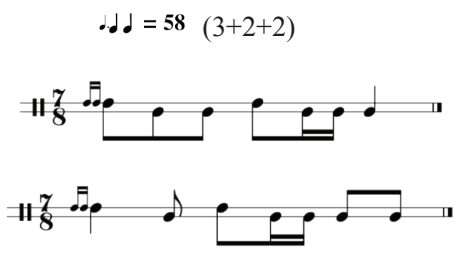

Tulum (gayda) eşliğinde oynanan oyunların tümüne "gayda" adı verilmektedir. Bir oyun değil, bir türdür. Bulgar oyunları gayda ile çalınıp oynanan hareketli oyunlardır ve Türklere oradan geçtiği düşünülmektedir (Demirsipahi 1975: 261). "Balkan Gaydası" bu örneklerden biridir.

12 Kabadayı Ahmet Bey: Üstad Naci ve Grubu. Geçmişten Geleceğe Otantik Folklorumuz Halaylarımız 2 Trakya Bölgesi. Emir Müzik (kaset).

13 Alay Bey (Bir Evler Yaptırdım): Üstad Naci ve Grubu. Geçmişten Geleceğe Otantik Folklorumuz Halaylarımız 2 Trakya Bölgesi. Emir Müzik (kaset). 
Nota 9-10. "Balkan Gaydası" ritim kalıplar1 ${ }^{14}$

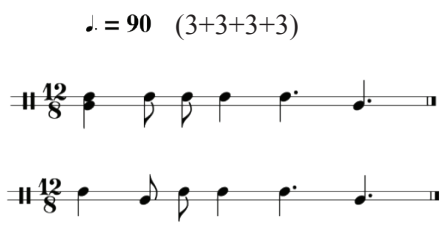

Kasap havası, kaval ile çalınan ezgilerin tümüne verilen addır (Demirsipahi 1975: 290). Kasaplık mesleğinden gelen bu havalar tüm Trakya'da yaygındır. Yunancada "kasapika", "hasapikos", Bulgarcada "kasapsko" olarak adlandır1lan kasap oyunları, kabadayılar gibi gerek Batı gerekse Doğu Trakya'da önemli bir yeri olan horo çeşitlerindendir. Oyunlar kendi aralarında üçe ayrılırlar: Tek bölümlüler: Oyun belli bir ezgi, ritim ve figürle baştan sona kadar oynanır. Sona gelirken aynı ezgi, ritim ve figürlerle hızı arttırılmış bir şekilde bir kez daha tekrarlanır. İki bölümlüler: İki ezgi, iki ritim, iki oyun ve iki tempo söz konusudur. Başta ezgi ağırdır, ikinci kısmına geçişte zurna ikinci ezgiye, davul ikinci ritme ve hızlı tempoya geçer. Bu bölüme "sirto" adı verilir. KasapSirto dansları metronom artışı farkıyla birbiri arkasından icra edilen müstakil dans formlarıdır. Üç bölümlüler: Üç ayrı ezgi, üç ayrı ritim ve üç ayrı oyundan oluşur. Birinci bölüm ağır oyun adı ile adlandırılır. Sirto olan ikinci bölümün ardından son bölümde ezgi, tartım, tempo ve oyun değişir. Tempo daha da hızlanır, tokmak vuruşları artar. Bu bölüme "susta" denilmektedir (Çolakoğlu 1984: 252-253). "Selanik Kasabı” ve "Eski Kasap” örnek olarak seçilmiştir.

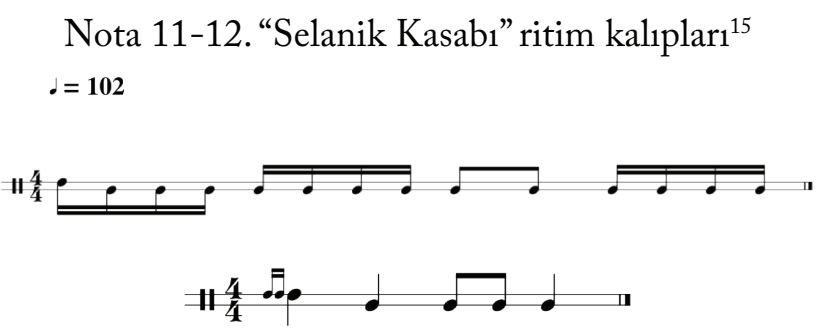

14 Balkan Gaydası: Trakyalı Metin Yanyacı ve Kardeşleri (kaset).

15 Selanik Kasabı: Kara Hüseyin Kırklarelili Osman Edirneli Rahmi ve Arkadaşları (kaset). 
Nota 13-14. "Eski Kasap" ritim kalıplar1 ${ }^{16}$

.$=130$

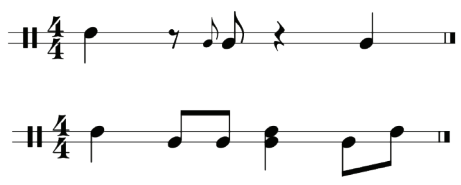

Düz hava olarak da adlandırılan ve çoğunlukla Trakya, Marmara, Ege ve Batı Karadeniz bölgelerinde görülen "karşılama", en az iki kişinin karşılıklı ve simetrik olarak oynadıkları oyunların genel adıdır ve anlatılmak istenen iki kişinin sohbetidir. Bu sohbet, iki genç, bir ihtiyar bir genç, iki ihtiyar, iki kadın, bir erkek bir kadın arasında olabilir (Çolakoğlu 1984: 246-247). Bir oyunun karşılama olabilmesi üç unsura bağlıdır: 9 zamanlı olması, karşlıklı oynanması, oyuncuların birbirlerine dokunmaması şeklindedir. Oyun akışı hızlı başlayıp hızlı biter (Ay 1999: 175). Yunanistan'da “antikrysto" veya "karsilamas" adıyla $(2+2+2+3)$ dağılımında çalınmaktadırlar. Nadiren 7/8'lik $(3+2+2)$ dağılımında yavaş tempoda oynanır. Bulgaristan'da da 7 zamanlı karşılamalara rastlanmaktadır ${ }^{17}$. "Bakkallar Satıyor Karaca Üzüm”, "Zigoş", "Yüksek Yüksek Tepelere Ev Kurmasınlar”, "Trakya Karşılaması”, "Kız Karşılama", "Dere Geliyor Dere", "Sülüman Aga" örnek olarak alınan eserlerdir.

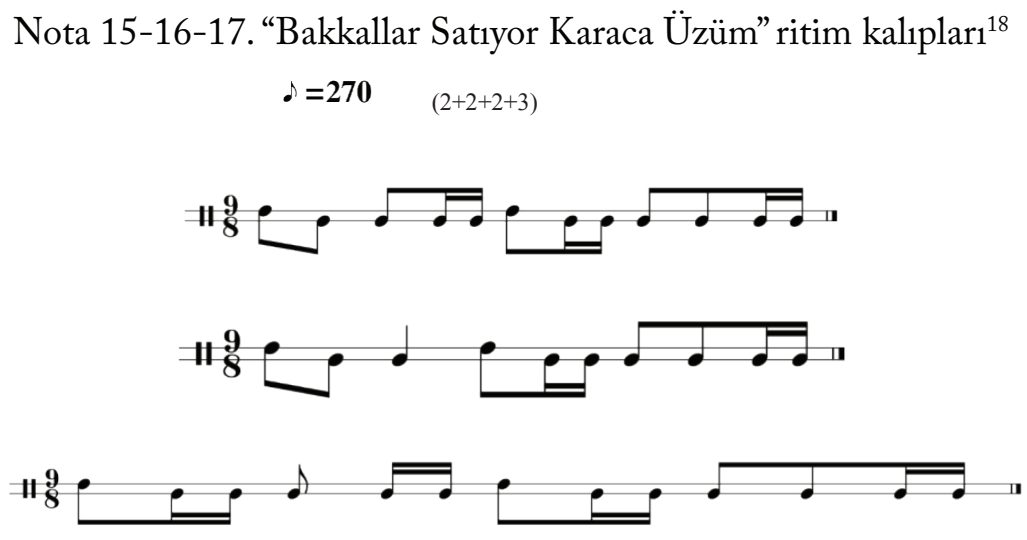

\footnotetext{
16 Eski Kasap: TRT arşivi. Kırıklareli Mahalli Havalar Davul: Süleyman Durmaz-Mehmet Karataş. 17 Music and Dance Tradition of Thrace, Greece's Northeastern Region. (http://www.ohfs.org).

18 Bakkallar Satıyor Karaca Üzüm: Edirneli Rahmi ve Arkadaşları (kaset).
} 
Nota 18-19-20. “Zigoş" ritim kalıplar ${ }^{19}$

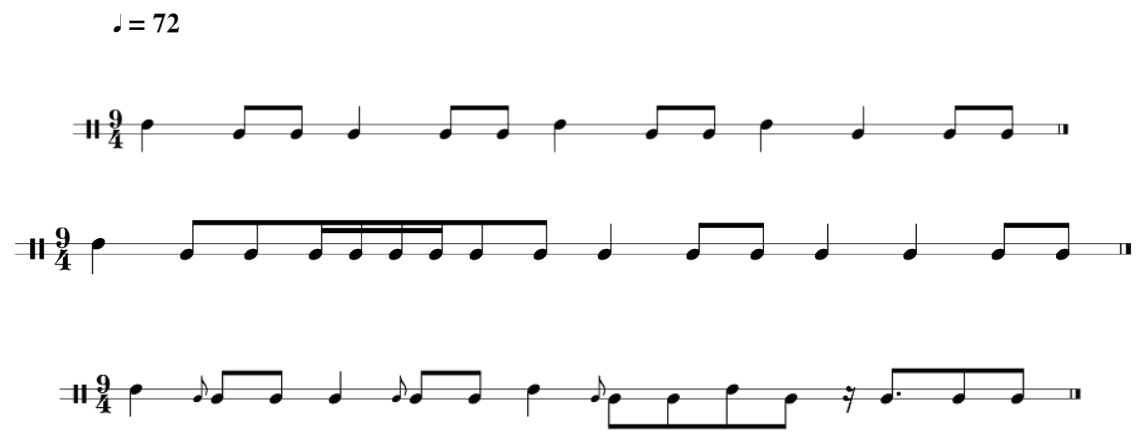

Nota 21-22. "Yüksek Yüksek Tepelere Ev Kurmasınlar" ritim kalıplar1 ${ }^{20}$ $\cdot=\mathbf{2 5 2}(2+2+2+3)$

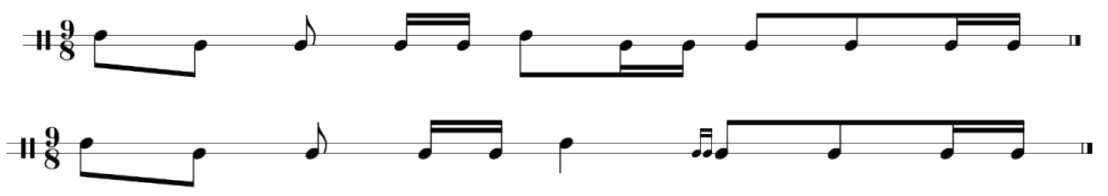

Nota 23-24. "Trakya Karşılaması" ritim kalıplar $1^{21}$ $\therefore=292 \quad(2+2+2+3)$
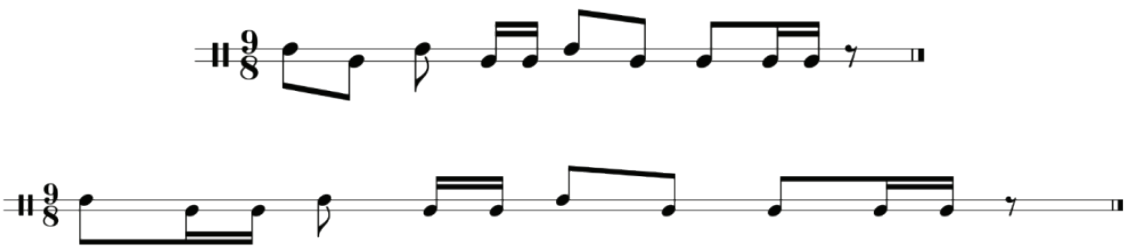

19 Zigoş: TRT arşivi. Kırıklareli Mahalli Havalar Davul: Süleyman Durmaz-Mehmet Karataş.

20 Yüksek Yüksek Tepelere Ev Kurmasınlar: Kara Hüseyin Kırklarelili Osman Edirneli Rahmi ve Arkadaşları (kaset).

21 Trakya Karşılaması: Üstad Naci ve Grubu. Geçmişten Geleceğe Otantik Folklorumuz Halaylarımız 2 Trakya Bölgesi. Emir Müzik (kaset). 
Nota 25-26. "Kız Karşılama” ritim kalıplar122

$\therefore=\mathbf{3 0 0}(2+2+2+3)$

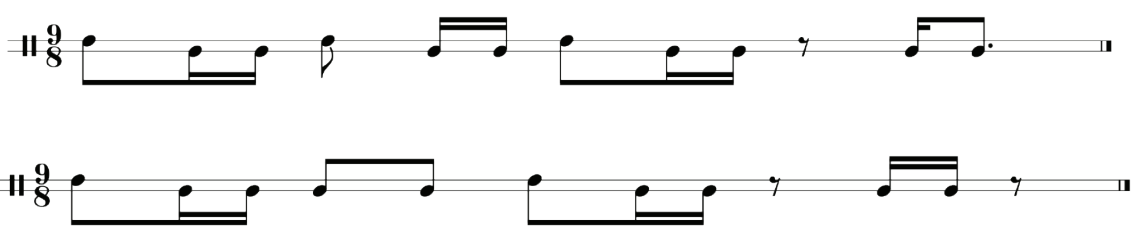

Nota 27-28. "Dere Geliyor Dere" ritim kalıplar123

.$\Rightarrow 296 \quad(2+2+2+3)$
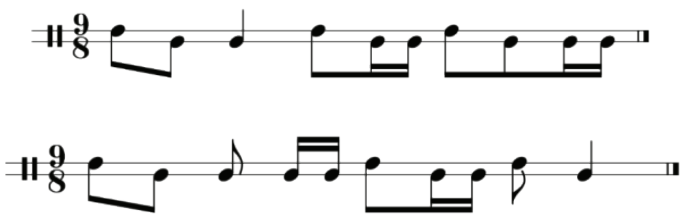

Nota 29. “Sülüman Aga” ritim kalıb1 ${ }^{24}$

ddd. $=48(2+2+2+3)$

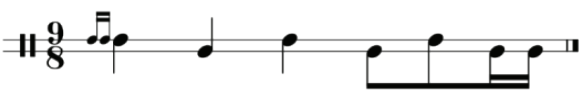

"Karaçalı", "Koşu Havası", "Çoban Havası", "Kurban” ve "Pehlivan Havaları" gibi salma havaları ise kabadayıca oynanan yiğitlik ve cengaverlik gösterileri ile bağlantılıdır (Gazimihal 1999: 142, Çolakoğlu 1984: 245, 246). Bu havalar Trakya kültürünün kimi bölgelerinde kısmen görülmektedirler. 7. Yüzyılda Traklar'ın Dobruca'ya göç etmesi, yerli halkla kaynaşmasına neden olmuş, burada ortak bir kültür gelişmiştir. Bu nedenle gerek Trakya'da gerek Dobruca'da atlı cirit oyunlarına rastlanmaktadır (Acaroğlu 1982: 13,14). Yu-

22 Kız Karşılama: Üstad Naci ve Grubu. Geçmişten Geleceğe Otantik Folklorumuz Halaylarımız 2 Trakya Bölgesi”, Emir Müzik (kaset).

23 Dere Geliyor Dere: Üstad Naci ve Grubu. Geçmişten Geleceğe Otantik Folklorumuz Halaylarımız 2 Trakya Bölgesi. Emir Müzik (kaset).

24 Sülüman Aga: Bölgelerimiz Türkülerimiz Trakya Yöresi. Davulcu: Hüseyin Somalı, Ulus Müzik (kaset). 
nanlılarda koşu havalarına "kousseftos" adı verilmektedir ${ }^{25}$. Salmaların içinde güreş havalarının ayrı bir yeri vardır. Güreşler, Bulgar, Yunan ve Osmanlı kültürünün en köklü geleneklerinden biridir. Yunanistan'da güreş dansları "palaistras" olarak geçmektedir ${ }^{26}$. Edirne'de yapılan ve kategorisinde en ünlü olan Kırkpınar güreşlerinde müzik, üç gün boyunca anonslar ve ağa seçimi dışında aralıksız çalınır. Genelde 20 davul ve 20 zurnacıdan kurulan ekipte, Roman müzisyenler çalar. Yörede "Dağlı" ve "Muhacir" olarak adlandırılan iki farklı Roman topluluğu söz konusudur (Yükselsin 2001: 137, 142). 93 Harbi'nde Yunanistan'ın Serez ve Drama bölgesinden gelenler "Muhacir", Bulgaristan'ın Deliorman bölgesinden gelenler "Dağlı" olarak anılırlar ${ }^{27}$. Karşılaşmalarda "Dağl1", "Muhacir” ve "Divan” olmak üzere üç temel güreş havası seslendirilir. "Pomak Güreşi”, "Adalı Halil Pehlivan Baş Güreş Havası”, “Karakucak Güreş Havası”, “Büyük Molla Güreş Havası”, “Köroğlu”, "Göksun Güreş Havası” gibi havalar genelde tüm güreşlerde çalınmaktaysa da Kırkpınar'da Rumeli türküleri de sıklıkla icra edilir. Güreş havalarında 2/4, 5/8, 9/8, 10/8, 12/2 gibi tartımlarda ritimler çalınır (Üngör 1992: 345). Karşılaşmanın kızıştığ zamanlarda ise 24/8'lik "Ceng-i Harbi” ritmine geçilir (Sarı 2002: 33). "Pehlivan Havası” örnek eser olarak seçilmiştir.

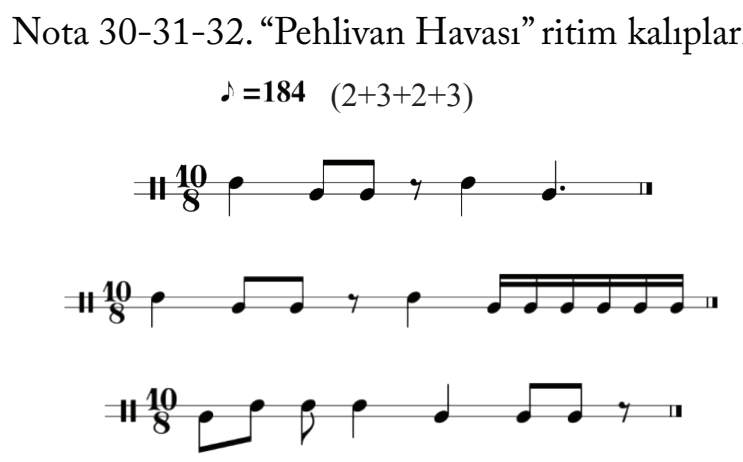

25 A Brief History Of Greek Music. https://www.helleniccomserve.com/musichistory.html

26 Music and Dance Tradition of Thrace, Greece's Northeastern Region. (http://www.ohfs.org).

2793 savaşından sonra göçler sonucu Edirne, Kırklareli, Tekirdağ’a gelenlerin birbirlerini Dramalı, Demreli, Pomak, Muhacir, Boşnak, Yugoslav göçmeni, Bulgar göçmeni vb diye anıp, çağırdıkları, bu grupların bazı köylerde karışık, bazı köylerde tamamen kendi topluluğu içinde yaşadıkları Öcal Oğuz tarafindan tespit edilmiştir (Oğuz, 1987, s. 121-123).

28 Pehlivan Havası: Kırkpınar Pehlivan Havaları ve Günümüz Folklor Oyunları I. (kaset). 


\section{SONUÇ}

Ritim bilgileri açısından bakıldığında dünya coğrafyası genelinde aksak tartımlar Trakya Bölgesi müziklerinin en karakteristik öğesidir. Doğu Trakyada 9 tartımlı ritimler daha sık çalınırlar. Batı Trakyada ise çoğunlukla karşılama havalarında görülürler. Buna karşın 7'liler doğuda daha az, batıda ise sık kullanılırlar. 11 ve ötesi için de benzer tespitte bulunmak mümkündür. Türk halk müziğinde 10 'lu tartım üzerindeki eserler nadirdir. Öte yandan $2,4,5$, 6 ve 10'lular tüm coğrafyada çalınırlar. Araştırmada 9 zamanlı eserlere daha geniş yer verilmiştir. 4, 7, 10 ve 12 zamanlı eserlerden de örnekler sunulmuştur. Örnek eserler şunlardır; Horolar: Fatoş (10/8), Edirne'nin Ardı Bağlar (9/8), Kabadayı Ahmet Bey (10/8), Alay Bey (7/8), Balkan Gaydası (12/8), Selanik Kasabı (4/4), Eski Kasap (4/4). Karş1lamalar: Bakkallar Satıyor Karaca Üzüm (9/8), Zigoş (9/4), Yürksek Yüksek Tepelere Ev Kurmasınlar (9/8), Trakya Karşılaması (9/8), Kız Karşılama (9/8), Dere Geliyor Gere (9/8), Sülüman Aga (9/8), Pehlivan Havası (10/8). Horolarda Kasap havalarında 4'lü, Kabadayı havalarında 10, 9 ve 7'li, Balkan Gaydası örneğinde de 12'li tartım yer almaktadır. 7/8'lik Alay Bey, Batı Trakya'da çokça çalınan $(3+2+2)$ şekliyle icra edilmiştir. Karşılamaların hepsi 9'lu zamanın $(2+2+2+3)$ şeklindeki dağılımındadır. Zigoş, 9/4'lük mertebe ile çalınmıştır. Salma sınıflamasında yer alan Pehlivan Havası ise 10/8'liktir ve $(2+3+2+3)$ dağılımındadır. Ritim kalıpları aynı eser içinde birbirinden farklı çeşitlemelerle çalınmakta, süslemeler için çarpmalar kullanılmaktadır.

Doğu Trakya’nın Edirne, Kırklareli ve Tekirdağ halk müzikleri üzerine yap1lan bu araştırma, bölgeye ait müzik kültürünün belli bir kesimini yansıtmaktadır. Diğer ülkelerde de yapılacak benzer uygulanmaların, Trakya kültür mirası adına ritmik yapıya ilişkin bilgi birikimi oluşturulması açısından faydalı olacağ1 düşünülmektedir. Elde edilecek bulgular, benzerlik ve farklılıkların ortaya konması açısından karşılaştırmalı müzikoloji çalışmaları için zengin bir veri tabanı oluşturacaktır. Aynı şekilde Anadolu'nun diğer coğrafi bölgelerinde de yapılacak çalışmalar, Anadolu'nun ritmik yapısını ortaya koyan, kültür mirasını yansıtan kaynak eserler yaratılmasını sağlayabilir. 


\section{KAYNAKLAR}

Acaroğlu, Türker (1982). "Balkan Halkbiliminde Türk Etkileri”. II. Milletlerarası Türk Folklor Bildirileri I. s 1-25.

Artun, Erman (1992). Tekirdağ Halk Oyunları Araştırması. Tekirdağ: Doğuş Tesisleri.

Ay, Göktan (1999). Folklor (Halkbilim). İstanbul: Pan Yayınları.

Aykent, Canan (2002). Asma Davulun Trakya Bölgesi’ne Özgü Ritmik Yapısı. (Yayımlanmamı̧̧ Yüksek Lisans Tezi), Hacettepe Üniversitesi, Ankara.

Çolakoğlu, Ömer (1984). Karşılama Türk Halk Bilimi ve Trakya Yöresinde Araştırmalar. İstanbul: Gümüş Basımevi.

Demirsipahi, Cemil (1975). Türk Halk Oyunları. Ankara: Türkiye İş Bankası Yayınları.

Duygulu, Melih (2006). Türkiye'de Cingene Müziği. Batı Grubu Romanlarında Müzik Kültürü. İstanbul: Pan Yayınları.

Gazimihal, Mahmut. Ragıp (1959). "Yurt Dı̧̧ında Türk Davulu”. Halkbilgisi Dergisi. Y11: 10, c. 5. s. 1-2

Ankara: Kültür Bakanlığı Yayınları.

(1999). Türk Halk Oyunları Kataloğu C.3.

Guboğlu, Mihail (1982). "Romen Folklorunda Türkler”. II. Milletlerarası Türk Folklor Kongresi bildirileri. s. 105-117.

Kösemihal, Mahmut Ragıp (1937). Balkanlarda Musiki Hareketleri. İstanbul: Numune Matbaası.

Oğuz,M. Öcal (1987). “Kırklareli’de Derlenen Bulgaristan Türklerinin Masal ve Türküleri”. Türk Folklorundan Derlemeler. s. 121-123.

Özkan, İsmail Hakkı (1994). Türk Mûsıkîsi Nazariyatı ve Usûlleri Kudüm Velveleleri. İstanbul: Ötüken Yayınları.

Sarı, Ayhan (2002). "Kırkpınar Güreş Müziği’nde Esrarengiz Ritm”. 641 Yıldır Yaşatılan Kırkpınar. s. 33.

Trærup, Birthe (1970). East Macedonian Folk Songs. Kopenhag: Akademisk Forlag.

Uğurlu, Nurer (2009). Folklor ve Etnografya Halk Türkülerimiz. İstanbul: Örgün Yayınevi. 
Üngör, Ethem Ruhi (1974). “Türk Davulu”. I. Uluslararası Türk Folklor Semineri Bildirileri: 8-14 Ekim 1973. S. 216-245.

(1985). “Türk Musikisinin Balkanlara Etkileri Arasında 11 Zamanlı Usul İlişkileri”. Türk Folkloru Araştırmaları 1985/2, s.119-132. (1992). "Pehlivan Musikisi". IV. Milletlerarası Türk Folklor Kültürü Kongresi Bildirileri C. 3. s. 343-370.

Yarkın, Ferruh (2014). Türk Müziğinde Usuller. İstanbul: Pan Yayınc1lık.

Yükselsin, İbrahim Yavuz (2001). "Bir Grup Kimliği Olarak "Çalgıcılık: Edirne Romanlarında Profesyonel Müzisyenliğin Grup Kimliğindeki Rolü”. Müzikoloji Dergisi Simpozyum Bildirileri, s, 134-140.

(2001). “Güreş Müziğinde İcra ve Yaratıc1lık: Edirneli Roman Müzisyenlerin Kırkpınar Güreşlerindeki Rolü”. Müzikoloji Dergisi Simpozyum Bildirileri, s, 141-147.

\section{İnternet Kaynaklanı}

Bugariska, Branka (1999). "Macedonian Traditional Vocalsinging”. (Erişim Tarihi: 12 Nisan 2001), http://blesok.mk/en/sound/reviews-sound/ macedonian-traditional-vocalsinging-09/

Kalliopi Stiga ve Evangelia Kopsalidou. "Music and Traditions of Thrace (Greece): A Trans- Cultural Teaching Tool 1". (Erişim Tarihi: 10 Aralik 2019), file:///C:/Users/User/Downloads/DialnetMusicAndTraditionsOfThraceGreece. 3825375.pdf

“A Brief History Of Greek Music”. (Erişim Tarihi: 08 Kasım 2019), https:// www.helleniccomserve.com/musichistory.html

"Music and Dance Tradition of Thrace, Greece's Northeastern Region”. (ErişimTarihi: 24 Aralık 2019), http://www.ohfs.org

“The Bulgarian Wedding”. (Erişim Tarihi: 28 Kasım 2019), http://ifccsa.org/ bulgfolk.html

“Zournas \& Daouli: An Inseparable Musical Tradition”. (Erişim Tarihi: 08 Kasım 2019), file:///C:/Users/User/Pictures/uhfds.pdf 


\section{EKLER}

Ritim kalıpları tespit edilen eserlerin ezgi notalarına ilişkin örnekler aşağıda yer almaktadır. Kalıplar, eserlerdeki reprise ve dal segno işaretlerinin birebir seslendirilmesine uygun olarak çözümlenmiş ve en çok tekrar edilenlere göre tespit edilmiştir. Örnek verilen eserlerin ezgileri Ali Fuat Aydın tarafindan notaya alınmıştır.

\section{Ek 1: Fatoş}

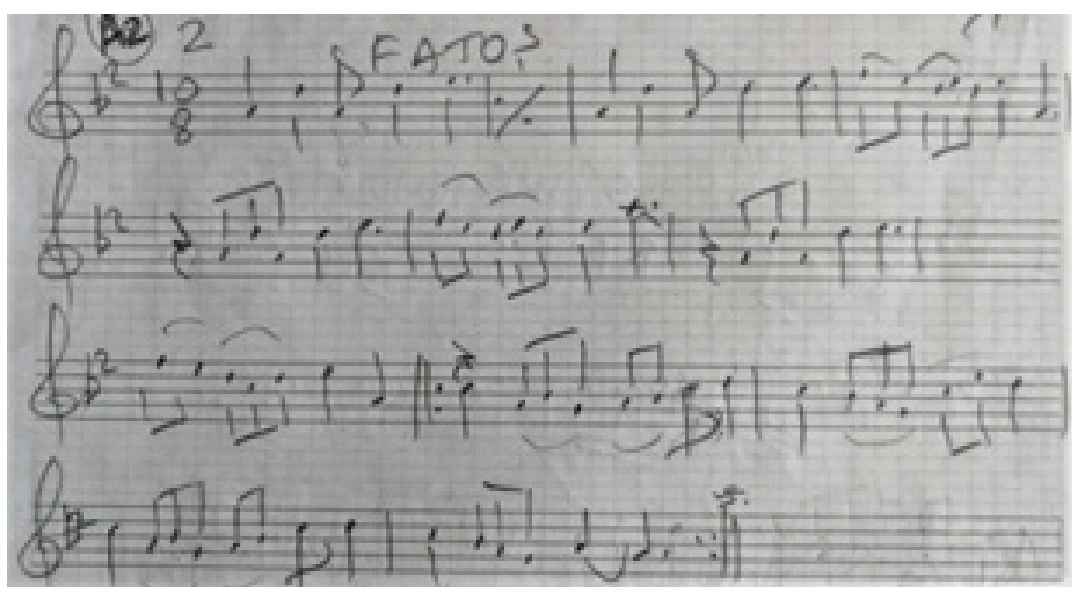

Ek 2: Edirne'nin Ardı Bağlar

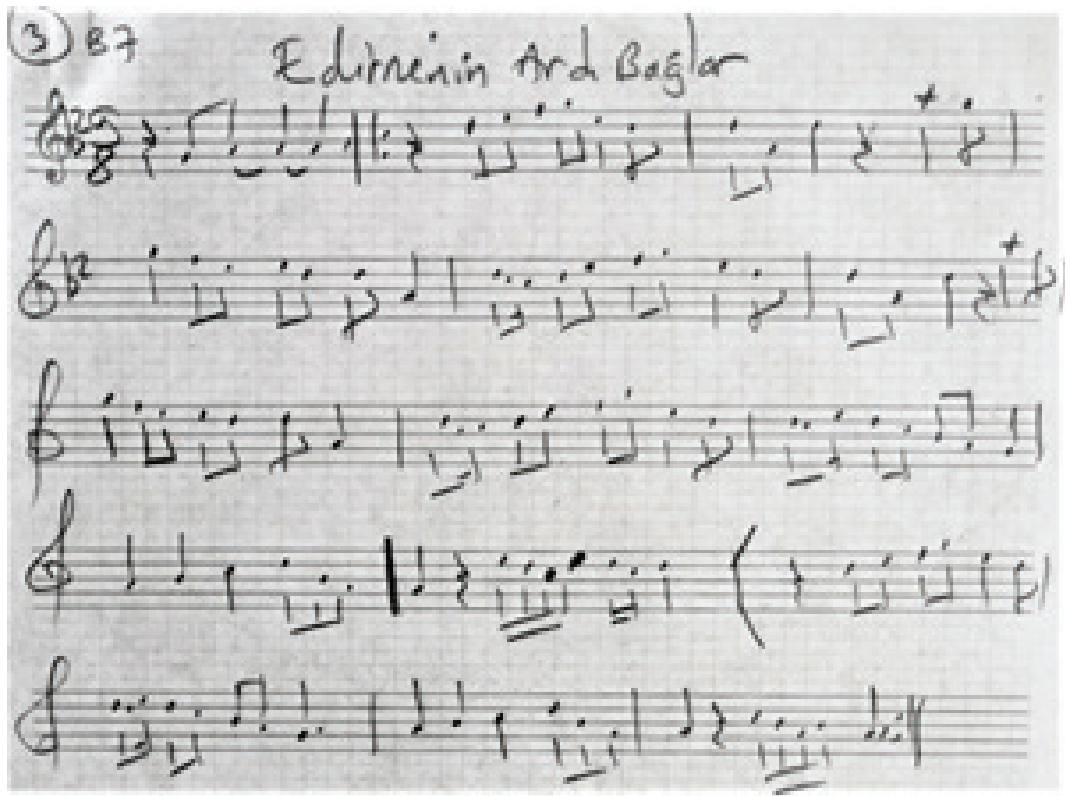




\section{Ek 3: Zigoş}

\section{2igor}

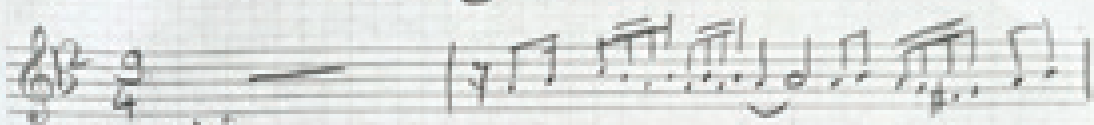
8 Gitis

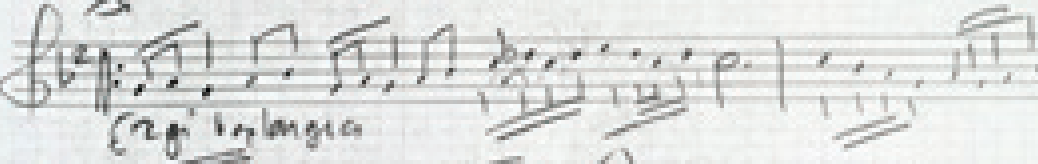

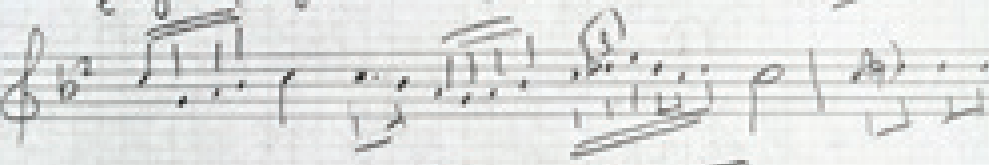

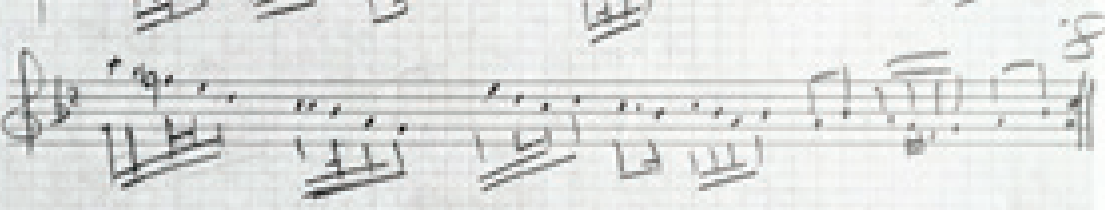

Ek 4: Sülüman Aga

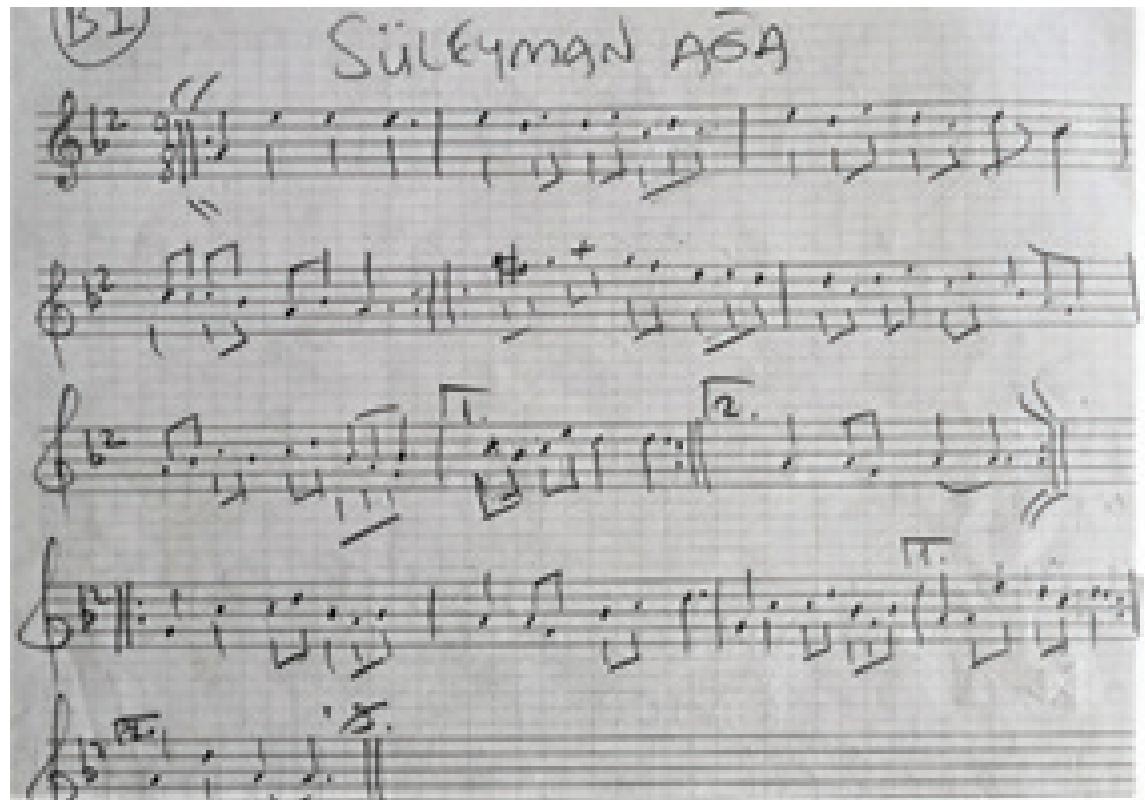




\section{Ek 5: Pehlivan Havası}

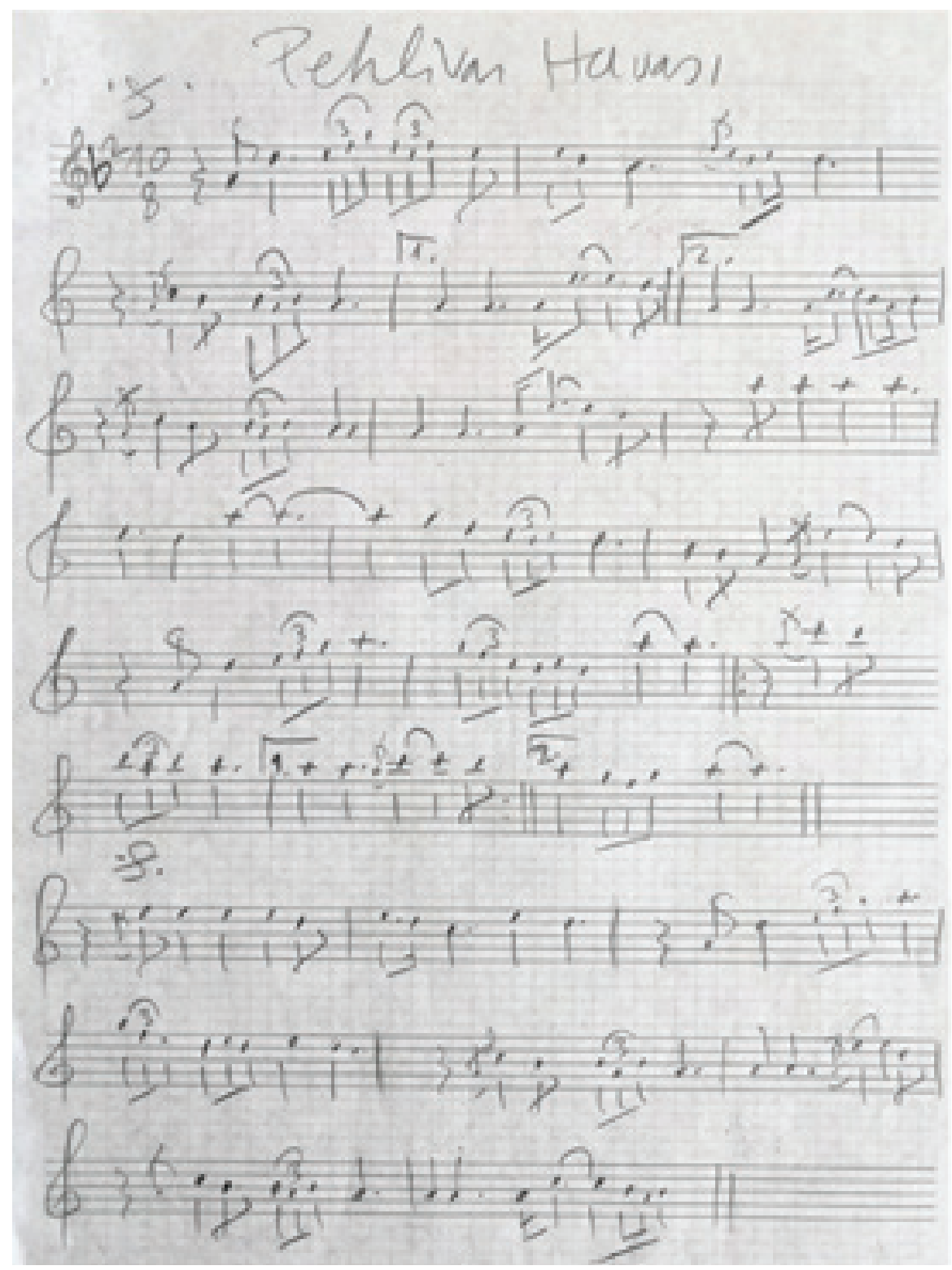


